\title{
Clostridium difficile - da legst di nieder!
}

\section{Im Zuge der Clostridien-Welle könnten demnächst einige Stellen im Labor abgebaut und dafür Hunde eingestellt werden.}

- Für Krankenhausdirektoren ergibt sich aus einer Beobachtung in einem holländischen Krankenhaus eine neue Sparmöglichkeit. Zur Einleitung hygienischer und präventiver Maßnahmen ist die frühzeitige Diagnosestellung bei Infektionen mit Clostridium difficile wichtig. Schnelltests und Enzymimmunoassays zum Nachweis des Clostridientoxins sind von begrenzter Sensitivität und Spezifität und vor allem teuer. Zytotoxische Assays in Zellkulturen dauern lange.

Erfahrenen Krankenschwestern und Ärzten ist der charakteristische Stuhlgeruch der Patienten mit Clostridium-Infektionen wohl bekannt. Warum sollte man daher nicht die Diagnose mithilfe eines Lebewesens vorverlegen, das bekanntlich 400-mal besser riechen kann als der Mensch?

Nach einem entsprechenden Training zur Erkennung von Stuhlproben von Patienten mit C.-difficile-Diarrhö nach dem Prinzip Belohnung, d. h. Leckerli bei Erfolg, durch einen professionellen Hundetrainer war ein zweijähriger Beaglehund in der Lage, C. difficile im Stuhl mit einer Sensitivität und Spezifität von nahezu $100 \%$ zu erkennen.

Der Hund war so trainiert, dass er sich beim Nachweis des typischen Ge- ruchs hinsetzte oder hinlegte. Diese Fähigkeiten wurden im Rahmen einer Riech-Visite auf den Stationen zweier großer Krankenhäuser in Holland eingesetzt. Der Hund wurde in die Zimmer von jeweils zehn Patienten geführt, von denen nur einer erkrankt war. Er erkannte 25 von 30 Fällen richtig positiv (Sensitivität $83 \%$ ) und 265 von 270 Kontrollen als richtig negativ (Spezifität 98\%).

Für diese überragenden diagnostischen Fähigkeiten benötigte der Hund weder Stuhlproben noch direkten physischen Kontakt mit dem jeweiligen Patienten. Daher konnte er auch hervorragend als Screening-Medium eingesetzt werden. Für die Geruchsvisite einer Station benötigt er nicht mehr als 10 Minuten.

\section{Kommentar}

Krankenhausdirektoren bekommen leuchtende Augen angesichts der bescheidenen Ansprüche solcher Mitarbeiter, die sich mit einem Stückchen Hundekuchen zufrieden geben. Kein Ärger mit dem TVÖD, dem Arbeitszeitgesetz, mit Urlaub, Krankheit und Schwangerschaft, nicht zu reden von den einfachen Unterbringungsmöglichkeiten.

\section{- M. K. Bomers}

(Korres.: m.bomers@vumc.nl): Using dog's superior olfactory sensitivity to identify Clostridium difficile in stools and patients: proof of principle study. BMJ 2012; 345: e7963.

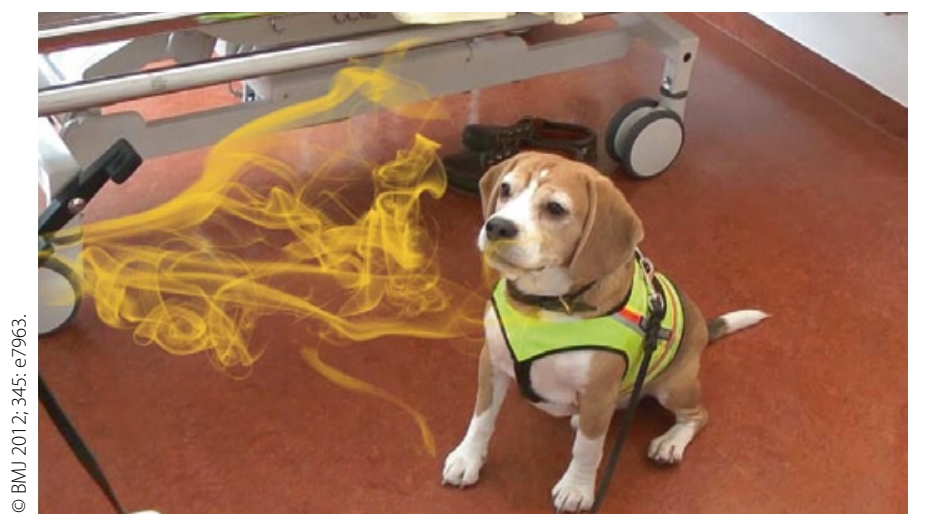

Gleich legt er sich hin: Cliff, der ClostridienSchnüffelhund. 